\title{
FRUITFULNESS OF RAJIV GANDHI JIVANDAYI YOJANA TO PATIENTS OF END-STAGE KIDNEY DISEASE TAKING DIALYSIS
}

\author{
Gajanan Gondhali' ${ }^{1}$ Susheel Bhattad ${ }^{2}$
}

${ }^{1}$ Associate Professor, Department of Medicine, MIMSR Medical College, Latur.

${ }^{2}$ Resident, Department of Medicine, MIMSR Medical College, Latur.

\section{ABSTRACT}

\section{BACKGROUND}

In recent era, incidence of CKD is increasing. Despite of it, very few patients seek Renal Replacement Therapy in India due to very high costs. Recently, Govt. of India has launched Rajiv Gandhi Jivandayi Yojana (RGJAY) Insurance Scheme for the poor.

Our study aims to know fruitfulness of this yojana to ESKD patients taking Renal Replacement Therapy in our rural area.

\section{MATERIALS AND METHODS}

Our study is a retrospective study. Data analysis of last 3 years was done. Incomplete data and patients having lost follow-ups were excluded from data analysis. We compared the data of ESKD patients before (one and a half year) and after (one and a half year) appliance of RGJAY to our institute; 32 patients were under dialysis before RGJAY out of 32, 11 patients continued to take dialysis under RGJAY; 46 new patients were added after appliance of RGJAY (total $57=11+46$ ). Our outcome was measured with variables like number of patients, follow-ups and advised dialysis frequency, adherence to the treatment, tendency to seek ICU care for complications, renal transplant and mortality. Statistical analysis was done with R programming. Chi square test was applied.

\section{RESULTS}

Number of patients of CKD increased from 32 to 57 after RGJAY. Average dialysis frequency increased from 61 per month to 252 per month. Average percentage frequency of dialysis done and advised rose from 38.29 to 91.4. It was proved statistically that number of patients taking ICU care as and when advised and having good drug adherence has been increased after RGJAY. Patients seeking vaccination (though not covered under RGJAY) and renal transplant has been increased from 2 to 35 and none to 6 . Still many deserving patients are unable to take these facilities, due to lack of documentation.

\section{CONCLUSION}

Rajiv Gandhi Jivandayi Yojana has been really jeevan daan to ESKD patients.

\section{KEYWORDS}

Rajiv Gandhi Jivandayi Yojana (RGJAY), ESKD, Renal Replacement Therapy.

HOW TO CITE THIS ARTICLE: Gondhali G, Bhattad S. Fruitfulness of Rajiv Gandhi Jivandayi Yojana to patients of end-stage kidney disease taking dialysis. J. Evolution Med. Dent. Sci. 2017;6(64):4649-4651, DOI: 10.14260/Jemds/2017/1005

\section{BACKGROUND}

In recent era, Chronic Kidney Disease (CKD) is an important cause of chronic disease globally.[1,2] Reason for increasing incidence of CKD is the increasing incidence of diabetes ${ }^{[1,3]}$ and hypertension[1,4,5] worldwide. In India, its rising incidence is likely to be a major problem in near future for both healthcare wise and economically. Indeed, it has been surveyed recently that the incidence rate of ESRD in India to be 229 per million populations, $[1,6]$ and more than one lakh new patients are enrolled in renal replacement programs yearly in India..11,7] Despite so much of disease burden, only $10 \%$ of the Indian ESRD patients hardly get any Renal Replacement Therapy (RRT).[1,7-9]

Cost for treatment of renal failure is very high in India. In a recent study, the monthly cost of the common dialysis prescriptions for two Haemodialysis (HD) sessions/ week

Financial or Other, Competing Interest: None.

Submission 17-06-2017, Peer Review 27-07-2017,

Acceptance 03-08-2017, Published 10-08-2017.

Corresponding Author:

Dr. Gajanan Gondhali,

Shrikrishna Medicare,

Opposite Bhattad Hospital,

Bus Stand, Latur-413512, Maharashtra.

E-mail: Shitalbhattadgondhali@gmail.com

DOI: $10.14260 /$ jemds $/ 2017 / 1005$ and 3 Peritoneal Dialysis (PD) exchanges/ day was estimated at Rs. 29,852 (USD 609) and 28,763 (USD 585), respectively.[10,11] Patients often cut down on dialysis frequency for economic reasons. Frequent and often longterm hospitalisations add to the financial burden. Medical costs are self-funded by a majority of patients, ${ }^{[10]}$ and such catastrophic expenses further push families deep into poverty.

For getting a transplant done costs around Rs. 4 lakhs on an average. After that per month recurring costs may vary from Rs. 5,000/- to Rs. 10,000/- depending upon the condition of the patient.[12]

A normal person in India cannot afford this extremely costly treatment. The problem is compounded by the fact that kidney failure is incurable. So these costs have to be borne till the patient passes away. This puts a perennial load on the patient and his/her family. This is the most important reason why only $2 \%-3 \%$ of kidney failure patients in India get treated. The rest die a very inhuman death.[12]

Our hospital is a tertiary care rural hospital where a wellestablished haemodialysis centre is there. Recently, one year back we have been benefited with Rajiv Gandhi Jivandayi Yojana. We are keen to know regarding fruitfulness of this yojana, especially for patients with ESKD requiring dialysis. 
RGJAY is an unique insurance scheme tailor made to meet the health demands of BPL (yellow card holders), APL (orange card holders), families with Antyodaya card holders \{whose income is less than 250 Rs. per month and those having Annapurna Cardholders (Shelterless people) for most common specialities requiring admission for surgeries and therapies. Scheme provides coverage upto 1,50,000 rupees per family per year. Exceptional package of rupees 2,50,000 is granted in case of renal transplant as immunosuppressive therapy is required for a period of one year.[13]

We hereby are keen to know about fruitfulness of this yojana for ESKD patients.

\section{MATERIALS AND METHODS}

Study Design- This is a retrospective observational study.

Data analysis of last 3 years was done. Incomplete data and patients having lost follow-ups were excluded from data analysis. We compared the data of ESKD patients before (one and a half years) and after (one and a half year) appliance of RGJAY to our institute; 32 patients were under dialysis before RGJAY. Out of 32, 11 patients continued to take dialysis under RGJAY; 46 new patients were added after appliance of RGJAY (total $57=11+46$ ). Our outcome was measured with variables like number of patients, follow-ups and advised dialysis frequency, adherence to the treatment, tendency to seek ICU care for complications, renal transplant and mortality. Statistical analysis was done with R programming. Chi square test was applied.

\section{RESULTS}

32 patients were under dialysis before RGJAY. Out of 32, 11 patients continued to take dialysis under RGJAY; 46 new patients were added after appliance of RGJAY (Total $57=11+$ 46).

Number of patients of CKD increased from 32 to 57 after RGJAY. Average dialysis frequency increased from 61 per month to 252 per month. Average percentage frequency of dialysis was done and advised rose from 38.29 to 91.4.

\section{Distribution of Patients}

$\mathrm{NR}=21$ (Old patients not under RGJAY).

$\mathrm{R}=46$ (New patients registered under RGJAY).

Old $\mathrm{R}=11$ (Old patients included in RGJAY after appliance of the scheme to institute).

\section{Observations in NR and R Groups}

We can see in Figure 1, mean of average frequency of visits in patients who were not registered under RGJAY was 3.285714 and for those under RGJAY was 6.347826. Statistical analysis was done using $\mathrm{R}$ programming. Fisher ' $\mathrm{t}$ ' test was applied and it was found to be statistically significant; $\mathrm{t}=-7.4349, \mathrm{df}=$ 52.096, $\mathrm{p}$-value $=9.928 \mathrm{e}-10$.

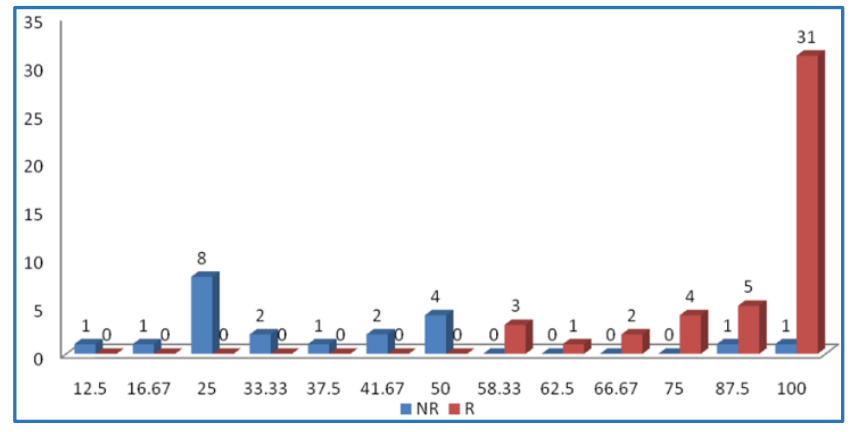

Figure 1. Percentage of Difference between Number of Visits advised and Actual Visits in Two Groups

Figure 1 shows that more number of patients following number of visits advised and actual visits in RGJAY group.

Death in Two Groups and Place of Demise in Two Groups We can see in Table 1 and 2. There is significant decrease in mortality of patients in RGJAY group as compared to Non RGJAY group. Also patients seeking hospital care has been increased, as there is significant increase in hospital deaths in RGJAY group.

\begin{tabular}{|c|c|c|c|}
\hline Status & Alive & Dead & Total \\
\hline Non RGJAY & 2 & 19 & 21 \\
\hline RGJAY & 36 & 10 & 46 \\
\hline
\end{tabular}

Table 1. Death in Non RGJAY and RGJAY Groups

Fisher's Exact Test was applied, p-value $=1.115 \mathrm{e}-07$

\begin{tabular}{|c|c|c|c|}
\hline Status & $\begin{array}{c}\text { Hospital } \\
\text { Deaths }\end{array}$ & $\begin{array}{c}\text { Non-Hospital } \\
\text { Deaths }\end{array}$ & Total \\
\hline Non RGJAY & 3 & 16 & 19 \\
\hline RGJAY & 8 & 2 & 10 \\
\hline
\end{tabular}

Table 2. Place of Demise in Non RGJAY and RGJAY Patients

P-value $=0.00131$

Tendency of Patients Seeking ICU Care as and when Advised

Though, all complications which requires ICU care are not covered under Jivandayi Yojana. Those patients requiring ICU care, tendency for seeking ICU care is seen in only 4 patients of total 21 patients who were not registered under RGJAY and which was 37 out of 46 registered RGJAY, which is statistically significant (Fisher's Exact Test for Count Data, pvalue $=4.646 \mathrm{e}-06)$.

\section{Drug Adherence in Two Groups}

We defined drug adherence to be good when patient was not missing a single dose of prescribed drug. We found that though only dialysis is covered under RGJAY scheme. Patients taking drugs, that is adherence to the treatment has been increased significantly. 


\begin{tabular}{|c|c|c|c|}
\hline Status & Bad & Good & Total \\
\hline Non RGJAY & 20 & 1 & 21 \\
\hline RGJAY & 5 & 41 & 46 \\
\hline \multicolumn{2}{|c|}{ Table 3. Drug Adherence in Two Groups } \\
\hline
\end{tabular}

Fisher's Exact Test for Count Data, $\mathrm{p}$-value $=1.73 \mathrm{e}-11$

\section{Hepatitis B Vaccination Status in Two Groups}

We advise hepatitis B vaccination to all patients with CKD on dialysis. We have seen there was significant increase in vaccination status of RGJAY group, though vaccination was not covered under Jivandayi yojana.

\begin{tabular}{|c|c|c|c|}
\hline Status & No & Yes & Total \\
\hline Non RGJAY & 19 & 2 & 21 \\
\hline RGJAY & 11 & 35 & 46 \\
\hline
\end{tabular}

Fisher's Exact Test for Count Data, $\mathrm{p}$-value $=3.884 \mathrm{e}-07$

Tendency of Patients for doing HCV Diagnostic Test in both the Groups

We do HIV status regularly in every patient undergoing dialysis. HCV testing was advised for all, but only 2 out of 21 were done. HCV testing before RGJAY and in RGJAY group all patients had undergone HCV testing before dialysis. Two were diagnosed as HCV positive.

\begin{tabular}{|c|c|c|c|}
\hline Status & No & Yes & Total \\
\hline Non RGJAY & 19 & 2 & 21 \\
\hline RGJAY & 0 & 46 & 46 \\
\hline Table 5. Tendency of Patients for \\
doing HCV Diagnostic Test in both the Groups \\
\hline
\end{tabular}

Fisher's Exact Test for Count Data, $\mathrm{p}$ - value $=8.695 \mathrm{e}-15$

\section{Number of Patients taking Erythropoietin Injections in} Two Groups

As we see in Figure 5, number of patients taking erythropoietin is 2 in Non RGJAY group and which is 30 in RGJAY group. Though expenses of taking injection erythropoietin has not been covered under Jivandayi yojana.

\section{Results in Old Patients included in RGJAY (Old R)}

11 patients who were with us before appliance of RGJAY to our hospital and who got registered under the scheme after this yojana became applicable to our college.

Results were compared before and after application of RGJAY in those patients, as Figure 3 shows there was significant improvement in average monthly dialysis visits and drug adherence, vaccination status and HCV testing. Results were statistically checked with the help of Welch Two Sample $\mathrm{t}$-test, $\mathrm{t}_{-}=-8.5347, \mathrm{df}=14.37, \mathrm{p}$-value $=5.283 \mathrm{e}-07$.

\section{DISCUSSION}

Though RGJAY scheme covered only dialysis in our institute, it has been shown a major impact on lives of CKD patients by increasing number of visits, drug adherence follow-ups, vaccination status, seeking ICU care, taking erythropoietin injections and after all survival. Limitations of RGJAY, 3 patients deserving for RGJAY scheme could not be enrolled in RGJAY due to lack of documentation.

\section{CONCLUSION}

We strongly support this scheme, as it is fruitful to CKD patients, really jivandayi to them. More and more hospitals should be having such scheme to reach the needy, especially rural hospitals.

\section{REFERENCES}

[1] Singh AK, Farag YM, Mittal BV, et al. Epidemiology and risk factors of chronic kidney disease in India - results from the SEEK (Screening and early evaluation of kidney disease) study. BMC Nephrology 2013;14:114.

[2] Ruggenenti P, Schieppati A, Remuzzi G. Progression, remission, regression of chronic renal diseases. Lancet 2001;357(9268):1601-8.

[3] Wild S, Roglic G, Green A, et al. Global prevalence of diabetes: estimates for the year 2000 and projections for 2030. Diabetes Care 2004;27(5):1047-53.

[4] Gupta R. Trends in hypertension epidemiology in India. J Hum Hypertens 2004;18(2):73-8.

[5] Anand MP. Prevalence of hypertension amongst Mumbai executives. J Assoc Physicians India 2000;48(12):1200-1.

[6] Modi GK, Jha V. The incidence of end-stage renal disease in India: a population-based study. Kidney Int 2006;70(12):2131-3.

[7] Kher V. End-stage renal disease in developing countries. Kidney Int 2002;62(1):350-62.

[8] Jha V. End-stage renal care in developing countries: the India experience. Ren Fail 2004;26(3):201-8.

[9] Sakhuja V, Sud K. End-stage renal disease in India and Pakistan: burden of disease and management issues. Kidney Int Suppl 2003;83(83):S115-8.

[10] Jha V. Current status of end-stage renal disease care in India and Pakistan. Kidney International Supplements 2013;3(2):157-60.

[11] Jeloka TK, Upase S, Chitikeshi S. Monthly cost of three sessions a day peritoneal dialysis is same as of thrice a week hemodialysis in self-paying Indian patients. Indian J Nephrol 2012;22(1):39-41.

[12] http://www.indiarenalfoundation.org

[13] Jeevandayee.gov.in. Rajiv Gandhi Jeevandayee Arogya Yojana 2015. https://www.jeevandayee.gov.in. 